\title{
Modelling and Simulating the Effect of Sunlight Heat on Front Bumper
}

\author{
Nagarjuna Reddy Mudem, S. P. Jani
}

\begin{abstract}
In this speeding modern world, it became a necessity to have at least one car for every family. There often comes the time when the car has to be parked in an open area due to space or parking unavailability. During daytime, the sunlight heat causes the car's exterior parts to get heated. Especially the summer heat in India is unbearable. The temperature rises too high that the stationery car's exterior parts can reach the temperature of $90^{\circ} \mathrm{C}$ (Considering the car is stationery for over a period of time). The parts of the car that are exposed to sunlight heat are Hood, Front and rear bumper, Doors and Roof area. Out of all the exterior parts, Bumper is plastic and it is the most important when it comes to style and safety. In this research the effect of Sunlight heat on Front bumper is studied. The problems associated with sunlight heat on Front bumper are; the front bumper goes out of its original shape, disturbs the Clearance (Gaps) and fitting with surrounding parts, if the surrounding parts are too stiff the Front bumper itself undergoes high deformation and high internal stresses will be developed at the mating regions.

In this research the FE modeling of Front bumper is done using ANSA software, the sunlight heat effect is simulated using ABAQUS solver. From the simulation results, there is $5.86 \mathrm{~mm}$ deformation observed on Front bumper, and at the mating regions (The region where Front bumper is surrounded by other parts like Head lamp, Hood, Wheel arch) there is a displacement of $3.39 \mathrm{~mm}$ (maximum clearance maintained at mating regions is $3 \mathrm{~mm}$ ).

Several countermeasures were studied and the best way to avoid the deformation is adding Honey-comb ribs, stiffeners at the mating regions.
\end{abstract}

Keywords: ABAQUS solver, ANSA software, countermeasure, Front Bumper, Honey-comb ribs, stiffeners.

\section{INTRODUCTION}

Bumper is a structure which is integrated with the front and rear ends of a car, so as to absorb impact in slow speed collisions, ideally to minimize the damage and reducing repair costs. Front bumper is very important when it comes to Pedestrian safety [1]. If the Bumper is too stiff, it won't absorb much of kinetic energy, it will cause serious injuries to the Pedestrian. Due to this, nowadays all the automobile manufacturers are using plastic Bumpers.

Revised Manuscript Received on December 30, 2019.

* Correspondence Author

Nagarjuna Reddy Mudem*, Pursuing Master of Technology, Department of CAD/CAM, Marri Laxman Reddy Institute of Technology and Management (MLRITM), Hyderabad (Telangana) India. E-mail: nagarjuna12892@gmail.com

S. P. JANI, Professor, Mechanical Engineering, , Marri Laxman Reddy Institute of Technology and Management (MLRITM), Hyderabad (Telangana) India.

(C) The Authors. Published by Blue Eyes Intelligence Engineering and Sciences Publication (BEIESP). This is an open access article under the CC BY-NC-ND license (http://creativecommons.org/licenses/by-nc-nd/4.0/)
Automobile manufacturers take extreme measures while manufacturing the automotive parts, to maintain gaps with certain tolerances between each assembly. Once the exterior parts of the car are manufactured, all the assemblies are brought together and assembled on the BIW (Body in White). Front bumper is surrounded by Head lights, Hood, Wheel arch, and Fender. An average gap of $3 \mathrm{~mm}$ is maintained at the mating regions of Front bumper and surrounding parts. This gap provided to make easy while fitting the Front bumper assembly on BIW. But due to outside sunlight heat, the Front bumper assembly expands and so the gap at interfaces will be reduced. If the expansion is above the gap value, it will generate internal stress in the Front Bumper.

The automobile industries are using CAE (Computer Aided Engineering) methods, CAE tools in the development phase of the vehicle for simulating many engineering problems. Using CAE tools is cost effective, and saves a lot of time, Designs can be modified any number of times. Such CAE tools ABAQUS, ANSA, HYPERMESH are used for the simulation of Sunlight heat on the Front Bumper.

After the simulation completes, the deformations at mating regions of Front bumper with other assemblies can be identified.

Different components that come under Front bumper assembly are:

1. Bumper Fascia

2. Upper radiator grill

3. Lower radiator grill

4. Diffuser

5. Fascia support

6. Absorber

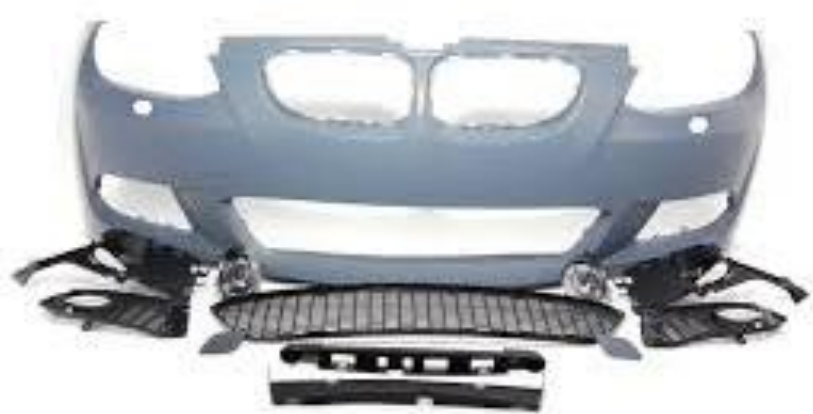

Fig. 1. Different components of Bumper

Parts surrounding Front bumper assembly are:

1. Head lamp

2. Hood

3. Fender (Metallic exterior part)

4. Wheel arch 
The first task is to develop an accurate model in order to obtain accurate results. Abaqus software has the capability to perform Thermo-mechanical analysis [2]. This procedure prescribes the methodology for numerical simulation of sunlight heat analysis for Front bumper. Following image shows the overview of procedure followed.

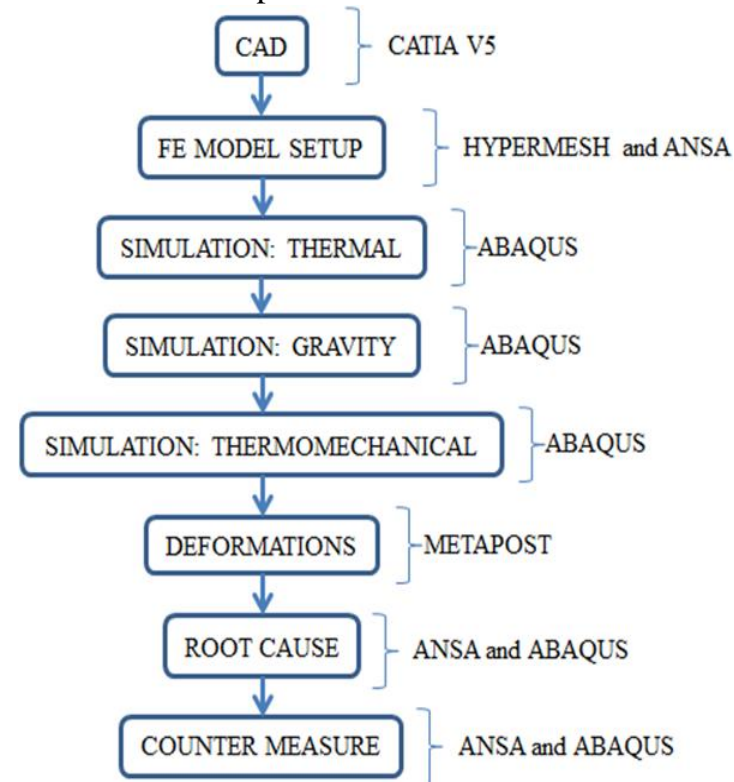

Fig. 2. Sequence of tasks followed in the analysis.

\section{METHODOLOGY AND MODEL PREPARATION}

The plastic material used in this kind of simulation is characterized in both elastic and plastic domains. This simulation considers the following calculus hypotheses. The sunlight heat simulation comprises three different analyses steps:

\section{A. Thermal-distribution analysis (Sunlight heat)}

The intention of this first analysis is to check the temperature distribution on Front bumper surface when it is subjected to sunlight heat. Heat flux from Sun light will be distributed over the surface due to conduction. Using a method of temperature stripes, it can be obtained the temperature distribution on the plastic Front bumper using ABAQUS solver [3]. A temperature gradient is defined, according to the part position with respect to the heating source.

- Temperature dependency (Ambient temperature is considered, $40^{\circ} \mathrm{C}$ ).

- Non-layered temperature gradient- only one layer (towards the interior of the car) of temperature is considered.

- Conduction-convection analysis is taken into account.

B. Gravity

To simulate the real time behavior, gravity also applied on the Front bumper.

\section{Thermo-mechanical analysis}

The data from thermal-distribution analysis will be used to initiate thermo-mechanical analysis. Thermo-mechanical analysis calculates how much the Front Bumper undergoes deformation due to the rise in temperature.

\section{MODEL OVERVIEW}

CAD (Computer Aided Design) is converted into FE (Finite Element) model using Pre-processor like Hypermesh and
ANSA. Following table gives the information about components considered in the analysis, and corresponding material used for the parts. To simplify the simulation, other parts like Hood, Fender, Head lights are not considered in the analysis. The area of study is only on the Front Bumper assembly. Localized BIW part is considered for fixation points.

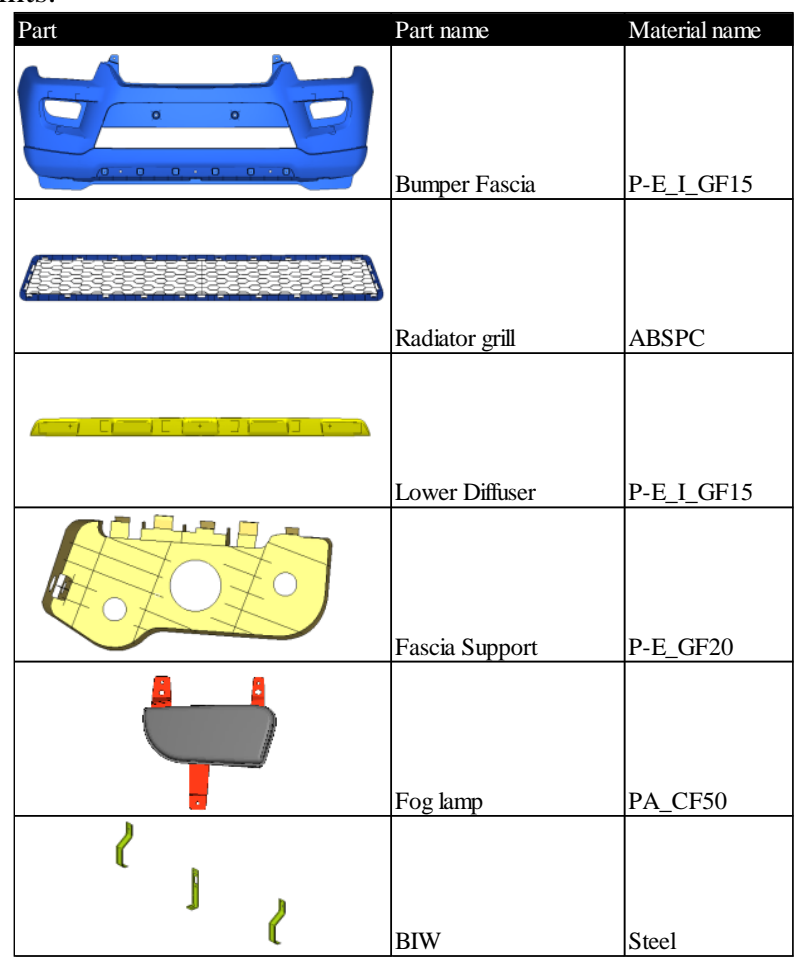

Fig. 3. Model components.

\section{MATERIALS}

The following table gives the information about Density, Young's modulus, Expansion coefficient, Conductivity and Poisson ratio for the materials [4] of Front Bumper.

Table- I: Material mechanical properties

\begin{tabular}{|c|c|c|c|c|}
\hline Material & $\begin{array}{c}\text { Density } \\
(* \mathrm{E}-9 \\
\mathrm{t} / \mathrm{mm} 3)\end{array}$ & $\begin{array}{c}\text { Elasticity } \\
(\mathrm{MPa})\end{array}$ & $\begin{array}{c}\text { Poisson } \\
\text { ratio }\end{array}$ & $\begin{array}{c}\text { Expansion } \\
\text { coeff. } \\
\left(/{ }^{\circ} \mathrm{C}\right)\end{array}$ \\
\hline ABSPC & 1.00 & $\begin{array}{c}2135 \text { at } 23^{\circ} \mathrm{C} \\
2030 \text { at } 40^{\circ} \mathrm{C} \\
1825 \text { at } 70^{\circ} \mathrm{C} \\
1475 \text { at } 100^{\circ} \mathrm{C}\end{array}$ & 0.3 & $6.50 \mathrm{E}-05$ \\
\hline & & $\begin{array}{c}2305 \text { at } 23^{\circ} \mathrm{C} \\
727 \text { at } 50^{\circ} \mathrm{C}\end{array}$ & 0.3 & $9.20 \mathrm{E}-05$ \\
P-E_GF20 & 1.05 & $\begin{array}{c}543 \text { at } 80^{\circ} \mathrm{C} \\
279 \text { at } 110^{\circ} \mathrm{C}\end{array}$ & & \\
\hline & & $\begin{array}{c}1517 \text { at } 23^{\circ} \mathrm{C} \\
647 \text { at } 50^{\circ} \mathrm{C} \\
323 \text { at } 80^{\circ} \mathrm{C}\end{array}$ & 0.3 & $8.01 \mathrm{E}-05$ \\
\hline P-E_I_GF15 & 0.9 & 189 at $110^{\circ} \mathrm{C}$ & & \\
\hline Steel & 7.85 & 210000 & 0.3 & $1.20 \mathrm{E}-05$ \\
\hline
\end{tabular}

The materials in the above table have plasticity [5] when stress developed is more than yield stress. The plasticity is temperature dependent, as the temperature raises the material weakens.

Published By: 


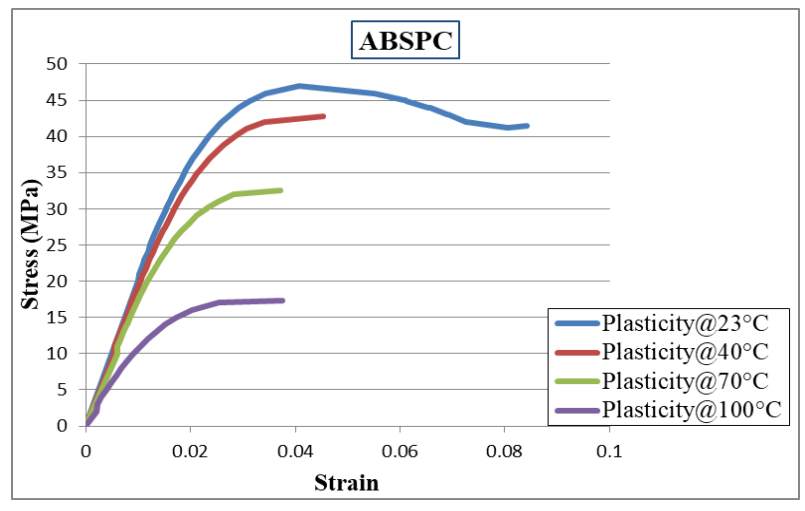

Fig. 4. Plastic curve of ABSPC material at different temperature conditions. (reference: www.matweb.com)

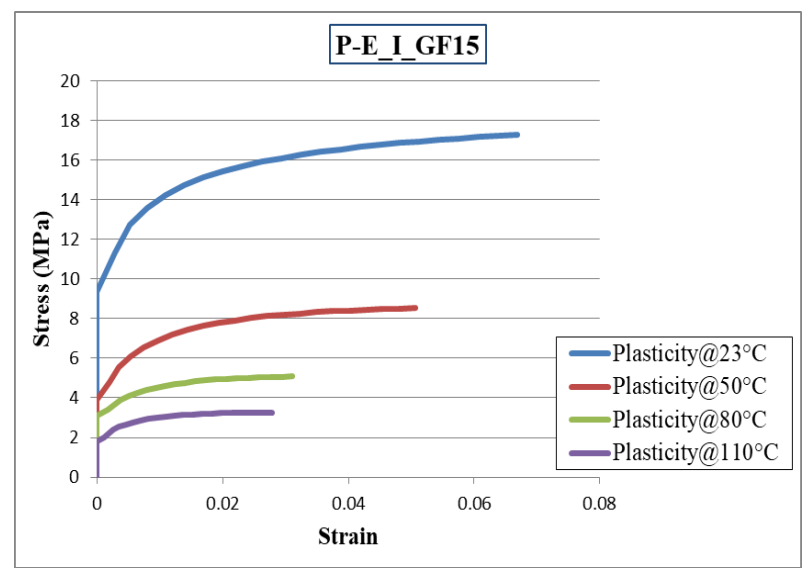

Fig. 5. Plastic curve of P-E_I_GF15 material at different temperature conditions. (reference: www.matweb.com)

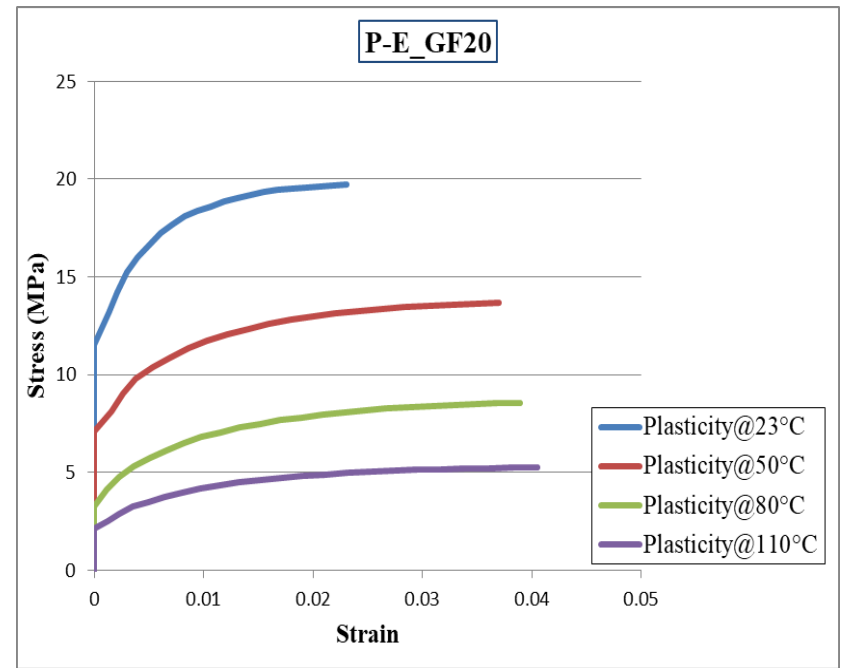

Fig. 6. Plastic curve of P-E_I_GF15 material at different

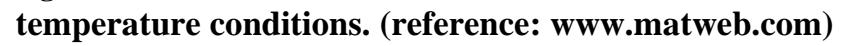

\section{SIMULATION $1^{\text {ST }}$ STEP: THERMAL-DISTRIBUTION ANALYSIS}

Once the meshing of each part in the Front bumper assembly is completed, all the components are grouped as one assembly. In this part of the analysis, no connections are considered. Model setup is done with the following steps.

A. Creation of temperature sets for heat distribution

The sunlight will not fall uniformly over the entire surface area of bumper; Area which is at the top will be exposed to high temperature when compared to lower portion. To simulate this, method of stripes will be used. Each stripe is defined with particular temperature. Between two stripes five or six rows of elements maintained to allow conduction.

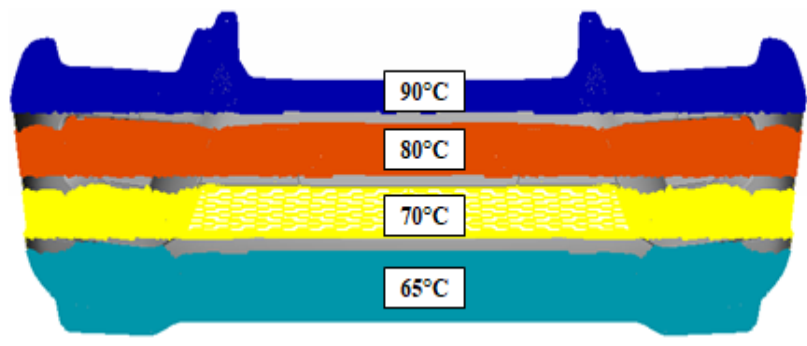

Fig. 7. Sets created for Front Bumper thermal analysis.

As shown in the figure, element sets are created for defining temperature. These sets (Temp_90, Temp_80, Temp_70, Temp_65) will be used to define a *FILM load. This card (FILM) [6] is used to define film coefficient and sink temperatures for heat transfer analysis.

\section{B. Initial conditions}

To simulate the ambient temperature, a set of nodes (Initial_temp) is created with all nodes of Font bumper. The ambient temperature $\left(40^{\circ} \mathrm{C}\right)$ [7] is considered as initial temperature for these nodes.

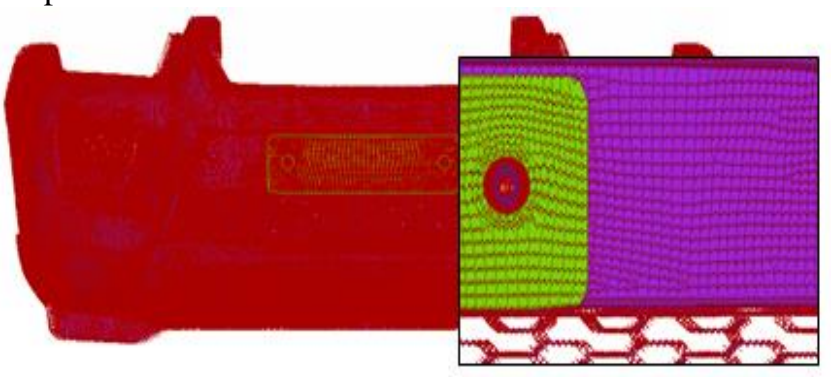

Fig. 8. Initial conditions (Graphic view).

In Abaqus code, this can be translated as:

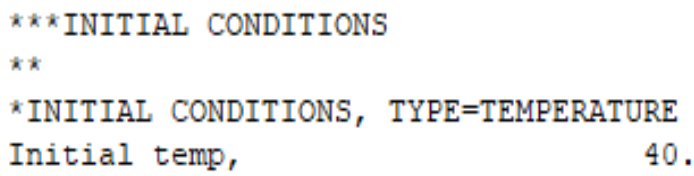

Fig. 9. Initial conditions (In ABAQUS).

C. Type of analysis used and parameters for the analysis Steady state heat transfer [8] is considered for the current simulation. In Abaqus this can be written as, *STEP, NAME=Thermal Distribution, AMPLITUDE=RAMP, UNSYMM=NO *HEAT TRANSFER, STEĀDY STATE

$$
0.1 \text {, }
$$

**

Fig. 10. Load step definition (in ABAQUS)

A temperature of $90^{\circ} \mathrm{C}$ is input on the surface with a convection coefficient of $50\left[\mathrm{~W} / \mathrm{m}^{2} / \mathrm{K}\right]$. The high coefficient value allows obtaining exact temperature on the selected area. In Abaqus code, this can be written as: 
**

*FILM

Temp_65, FPOS,

Temp 70 , FPOS

Temp 80, FPOS,
Temp_90, FPOS,

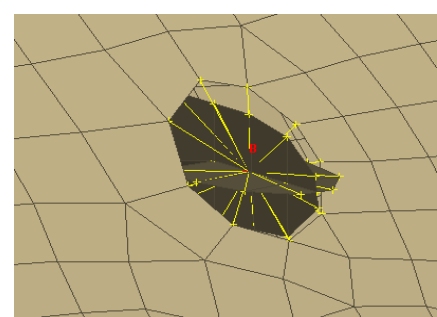

Fig. 16. Bolt connection representation.

For the present analysis, the material conductivity is considered to be constant throughout the heating process. By default, $0.27[\mathrm{~W} / \mathrm{m}-\mathrm{K}]$ has been assigned as conductivity [9] for plastic materials. With this, model setup is completed and it is ready to be simulated in ABAQUS solver.

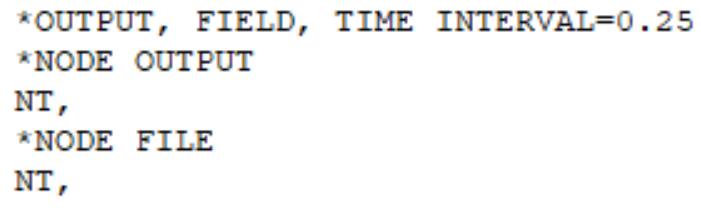

\section{SIMULATION 2 ${ }^{\text {ND }}$ STEP: GRAVITY SIMULATION}

Gravitational pull on the assembly has also to be considered in the analysis. The acceleration due to gravity $\mathrm{g}=9.81 \mathrm{~m} / \mathrm{s}^{2}\left(9810 \mathrm{~mm} / \mathrm{s}^{2}\right)$. In simulation gravity is applied in negative Z-direction on all the elements. Gravitational force acting on each element is, $\mathrm{F}=\mathrm{mg}\left(\mathrm{g}=9810 \mathrm{~mm} / \mathrm{s}^{2}\right)$.

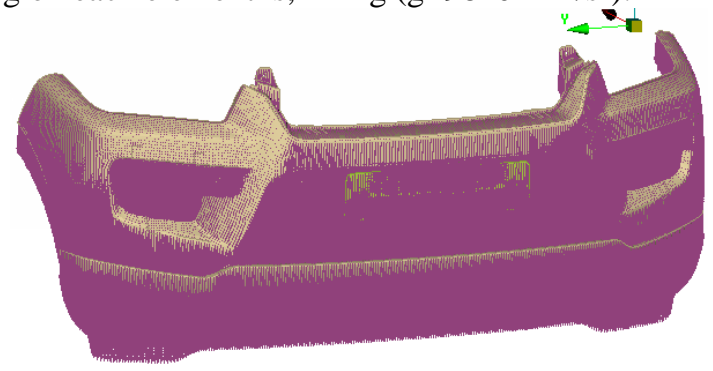

Fig. 13. Gravity load on the model.

In Abaqus code, this can be written as:

**

$* \star$ DLOAD $\quad($ TYPE $=$ GRAV $)$

$* *$

*DLOAD

，GRAV, 9810.,

$0 .$,

Fig. 14. Gravity load on the model (in ABAQUS).

\section{A. Screws}

Model used in the Thermal-distribution simulation is without any connections or boundary conditions. But for the Gravity and Thermo-mechanical simulations, it is also necessary to consider Bolts, Snap fits, Clips and connections with BIW. All these connections are given in the form of *.MPCs (Multi Point Constraints).

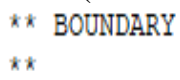

Fig. 15. Boundary conditions (in ABAQUS).

\section{B. Boundary condition}

Apply a boundary condition on the COG of the MPC blocking all degrees of freedom (wherever fixations with BIW come).

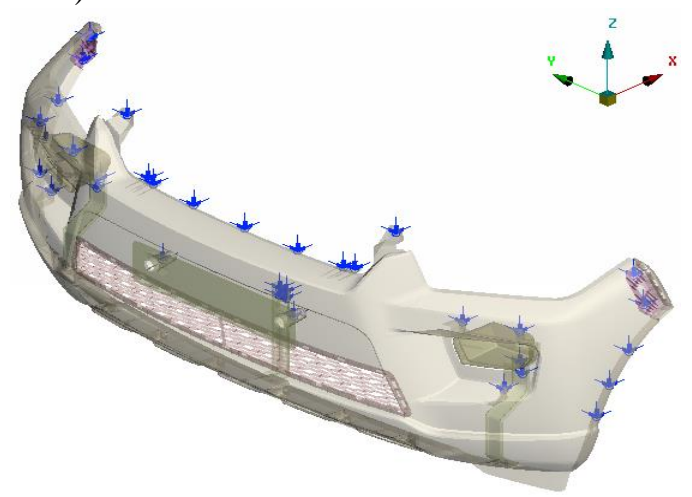

Fig. 17. Boundary conditions.

\section{SIMULATION $3^{\mathrm{RD}}$ STEP: THERMO-MECHANICAL ANALYSIS}

Thermo-mechanical analysis is followed by the gravity simulation. In this simulation, Thermal distribution results are used as input. Temperature distributed over the surface induces deformation (Due to expansion) [10]. This temperature coupled displacement analysis works on the following equation [11]. The stress $\sigma_{\mathrm{ij}}$ is calculated using the strain $\varepsilon_{\mathrm{ij}}$ and temperature variation $\Theta=\mathrm{T}-\mathrm{T} 0$ between two consecutive states.

$$
\begin{array}{r}
\varepsilon_{\mathrm{ij}}=\mathrm{C}_{\mathrm{dil}} \Theta \sigma_{\mathrm{ij}} \\
\mathrm{C}_{\mathrm{dil}}=\text { material expansion co-efficient }
\end{array}
$$

\section{A. Step parameters and output requests}

Load step defined is as follows,

In Abaqus code, this can be translated as:

*STEP， NAME=Thermo-mechanical， AMPLITUDE=RAMP， NLGEOM=YES， UNSYMM=NO *STATIC

$$
\begin{array}{llll}
0.1, & 1 ., & 1 . \mathrm{E}-5, & 0.1
\end{array}
$$

Fig. 18. Load step (in ABAQUS).

Along with Gravity, thermal load is also acted on the front bumper assembly Temperature load defined in ABAQUS is written as,

** TEMPERATURE

**

*TEMPERATURE, FILE=Front-Bumper Thermal distribution,fil

Fig. 19. Thermal load (in ABÄQUS).

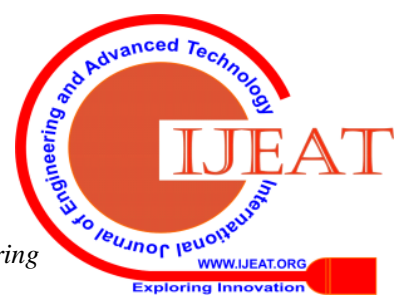


File is the output of First analysis. Thermo-mechanical simulation is simulated and the results are validated using METAPOST.

\begin{tabular}{|c|c|c|}
\hline II Front-Bumper_Thermal_distribution & 10/28/2019 12:06 ... & MS-DOS Applicati... \\
\hline 挋 Front-Bumper_Thermal_distribution & 10/28/2019 12:11 ... & DAT File \\
\hline Front-Bumper_Thermal_distribution.fil & 10/28/2019 12:11 ... & Fll File \\
\hline 㔲 Front-Bumper_Thermal_distribution & 10/29/20193:10 PM & INP File \\
\hline$\triangle$ Front-Bumper_Thermal_distribution & 10/28/2019 12:11 ... & Outlook Item \\
\hline Front-Bumper_Thermal_distribution & 10/28/2019 12:11 ... & ODB File \\
\hline Front-Bumper_Thermal_distribution.prt & 10/28/2019 12:11 ... & PRT File \\
\hline [] Front-Bumper_Thermal_distribution.sim & 10/28/2019 12:11 ... & SIM File \\
\hline 茞 Front-Bumper_Thermal_distribution & 10/28/2019 12:11 ... & STA File \\
\hline
\end{tabular}

Fig. 20. Thermal loading-*.fil file.

\section{RESULTS AND DISCUSSION}

\section{A. Results of Thermal-Distribution}

Once the model is submitted in ABAQUS solver, using *HEAT TRANSFER (STEADY STATE) analysis method [12], temperature is distributed over the surfaces using thermal conductivity $(0.27 \mathrm{~W} / \mathrm{mm}-\mathrm{K})$ and convective heat transfer coefficient of $\left(50 \mathrm{~W} / \mathrm{m}^{2}-\mathrm{K}\right)$. Since thickness is very small, temperature variation across the thickness is ignored. I.e. Same temperature on the thickness is considered.

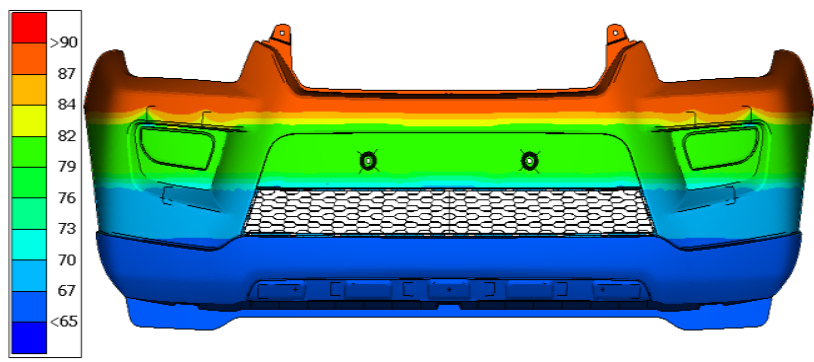

Fig. 21. Temperature distributions on surface (Front Bumper Front view).

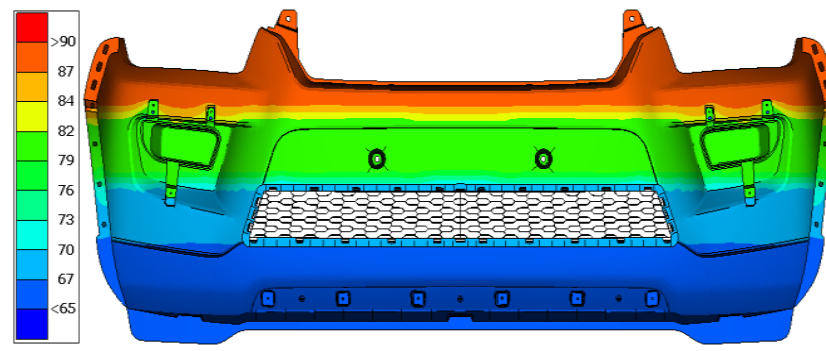

Fig. 22. Temperature distributions on surface (Front Bumper Rear view).

The temperature distribution obtained in the first part of analysis is used for Gravity loading and consequently Thermo-mechanical loading. The output file *.file is used as input for the Thermo-mechanical simulation.

\section{B. Results of Gravity simulation}

Displacement is observed after Gravity is applied on the Front bumper assembly.

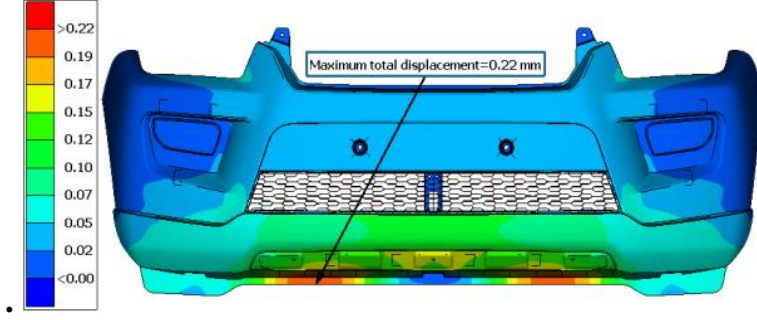

Fig. 23. Maximum Total displacement observed.

C. Results of Thermo-mechanical simulation

1) TOTAL-DISPLACEMENT

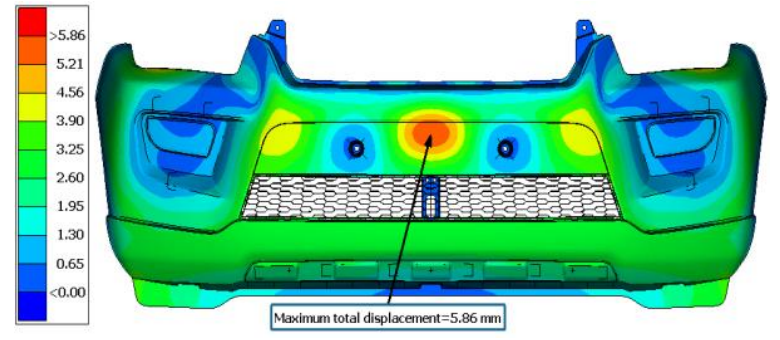

Fig. 24. Maximum total displacement results.

2) DISPLACEMENTS ABOVE 3mm

Displacements are more than $3 \mathrm{~mm}$ observed at different regions of Fascia. Red color at mating regions indicates NG (Not Good). At Head lamp and Wheel Arch region there is red color.

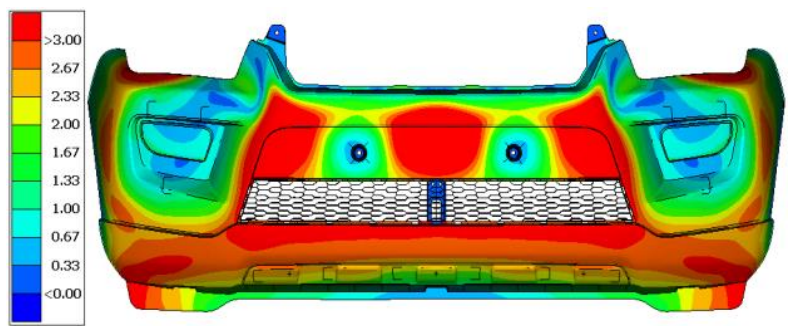

Fig. 25. Displacement results above $3 \mathrm{~mm}$.

\section{RESULTS AT INTERFACES OF OTHER PARTS}

\section{A. BUMPER-HEAD LAMP}

Displacements are measured at Bumper-Head lamp mating regions.

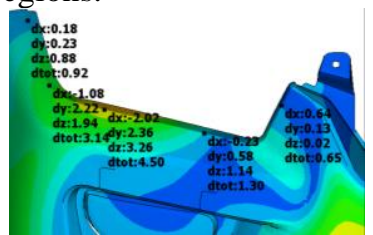

LH Head lamp

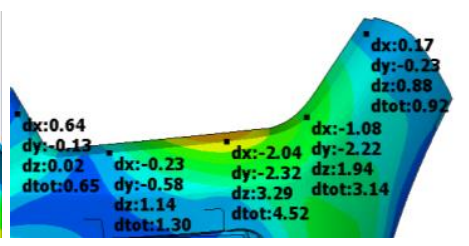

RH Head lamp
Fig. 26. Displacements Bumper-Head lamp interface.

LH-Left Hand side, RH-Right hand side; X-direction (Fitting direction), $\mathrm{Y}$ and $\mathrm{Z}$-directions (Clearance direction)

Maximum displacement is $2.04 \mathrm{~mm}$ in $\mathrm{X}$-direction, Maximum displacement is $2.36 \mathrm{~mm}$ in $\mathrm{Y}$-direction, Maximum displacement is $3.29 \mathrm{~mm}$ in Z-direction.

The fitting is OK but clearance is NG in Z-direction at Bumper-Head lamp region.

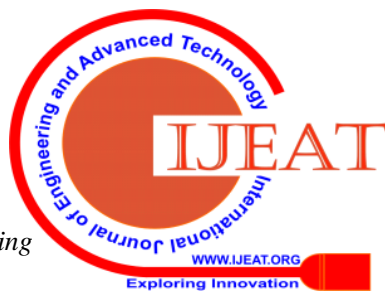




\section{B. BUMPER-HOOD}

Displacements are measured at Bumper-Hood mating regions.

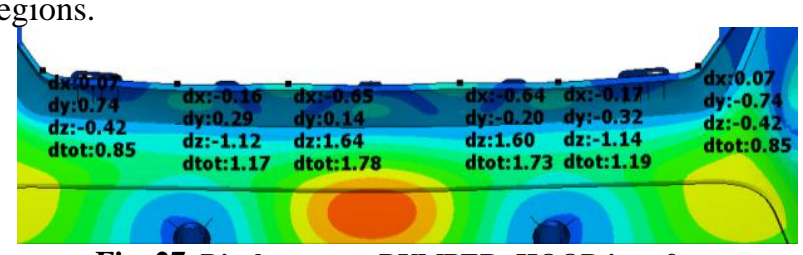

Fig. 27. Displacements BUMPER- HOOD interface.

Maximum displacement is $\mathbf{0 . 6 5} \mathrm{mm}$ in $\mathrm{X}$-direction, Maximum displacement is $\mathbf{0 . 7 4} \mathrm{mm}$ in Y-direction, Maximum displacement is $1.64 \mathrm{~mm}$ in Z-direction.

The fitting and clearance is OK between Bumper-Hood regions.

\section{BUMPER-FENDER}

Displacements are measured at Bumper-Fender mating regions.
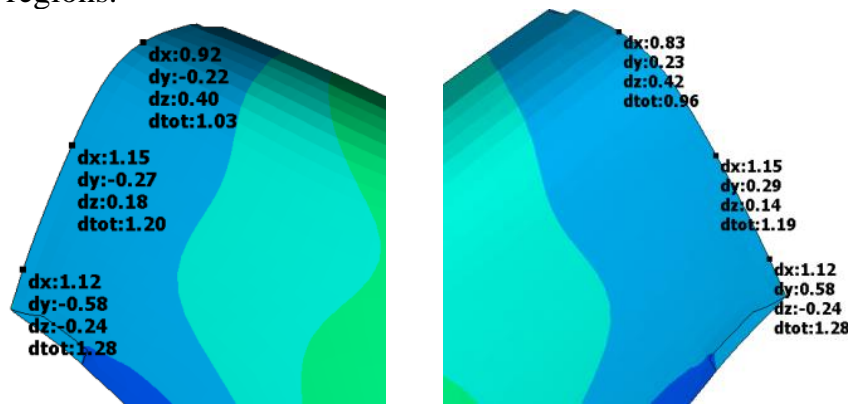

LH Bumper-Fender RH Bumper-Fender

Fig. 28. Displacements Bumper- Fender interface.
Maximum displacement is $1.15 \mathrm{~mm}$ in $\mathrm{X}$-direction,

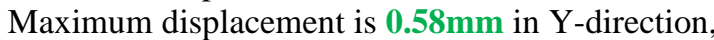
Maximum displacement is $1.28 \mathrm{~mm}$ in Z-direction.

The fitting and clearance is OK between Bumper-Fender regions.

\section{BUMPER-WHEEL ARCH}

Displacements are measured at Bumper-Wheel arch mating regions.

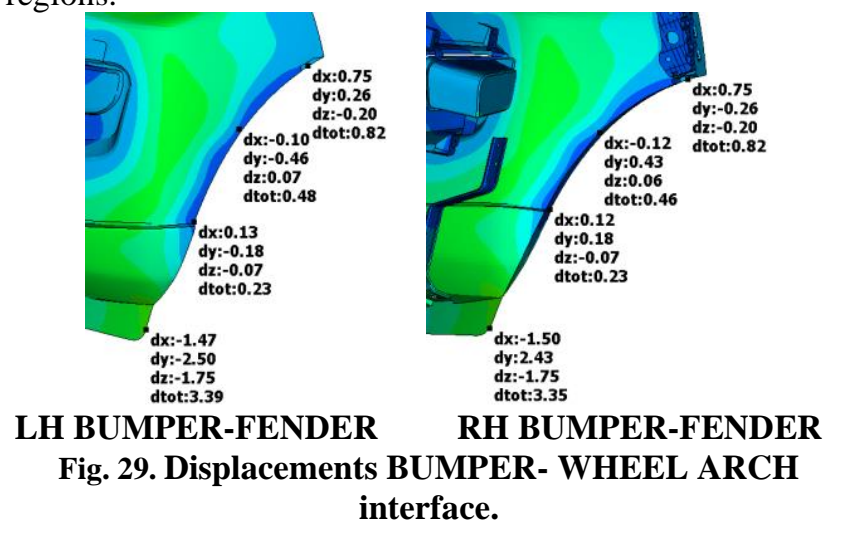

Maximum displacement is $1.50 \mathrm{~mm}$ in $\mathrm{X}$-direction, Maximum displacement is $2.50 \mathrm{~mm}$ in $\mathrm{Y}$-direction, Maximum displacement is $3.39 \mathrm{~mm}$ in Z-direction.

The fitting is OK but clearance is NG in Z-Direction at Bumper-Wheel arch regions.

Table- II: Fitting and Clearance values at mating regions (Summary of results)

\begin{tabular}{|c|c|c|c|c|}
\hline ZONE ID & Region & $\begin{array}{c}\text { FITTING } \\
\text { DIRECTION }\end{array}$ & $\begin{array}{l}\text { CLEARANCE } \\
\text { DIRECTION }\end{array}$ & $\begin{array}{l}\text { CLEARANCE } \\
\text { DIRECTION }\end{array}$ \\
\hline ZONE 1 & BUMPER-HEAD LAMP & $2.04 \mathrm{~mm}$ & $2.36 \mathrm{~mm}$ & $3.29 \mathrm{~mm}$ \\
\hline ZONE 2 & BUMPER-HOOD & $0.65 \mathrm{~mm}$ & $0.74 \mathrm{~mm}$ & $1.64 \mathrm{~mm}$ \\
\hline ZONE 3 & BUMPER-FENDER & $1.15 \mathrm{~mm}$ & $0.58 \mathrm{~mm}$ & $1.28 \mathrm{~mm}$ \\
\hline ZONE 4 & $\begin{array}{c}\text { BUMPER-WHEEL } \\
\text { ARCH }\end{array}$ & $1.50 \mathrm{~mm}$ & $2.50 \mathrm{~mm}$ & $3.39 \mathrm{~mm}$ \\
\hline
\end{tabular}

\section{CONCLUSION}

In this study the behavior of Front bumper is analyzed when it is subjected to sunlight heat. High deformation mating regions are located. By making the following changes, maximum displacement can be reduced.

1. by adding Honeycomb ribs on inner surface.

2. by increasing thickness at localized regions.

3. by adding stiffeners and ribs.

But adding stiffness to the bumper is a negative point of view when it is seen from Pedestrian safety, keeping the pedestrian safety also into consideration, stiffness changes can be done.

\section{REFERENCES}

1. Pedestrian safety regulation is considered from https://www.nhtsa.gov/road-safety/pedestrian-safety.

2. Sequentially coupled thermal-stress analysis in ABAQUS: https://abaqus-docs.mit.edu/2017/English/SIMACAEANLRefMap/si maanl-c-thermstressanal.htm.

3. CAE tool capabilities extracted from https://www.3ds.com/products-services/simulia/products/abaqus/
4. Material data taken from https://www.campusplastics.com/.

5. Plastic data taken from http://www.matweb.com/.

6. Film coefficients and sink temperatures for fully coupled thermal-stress analysis: https://abaqus-docs.mit.edu/2017/English/SIMACAEKEYRefMap/si makey-r-film.htm.

7. Ambient temperature definition: http://web.mit.edu/calculix_v2.7/CalculiX/ccx_2.7/doc/ccx/node215.h $\underline{\mathrm{tml}}$

8. Heat transfer analysis procedures, overview in ABAQUS http://dsk.ippt.pan.pl/docs/abaqus/v6.13/books/usb/default.htm?startat =pt04ch16s01at39.html.

9. Thermal conductivity of plastics https://www.nuclear-power.net/nuclear-engineering/heat-transfer/ther mal-conduction/thermal-conductivity/thermal-conductivity-of-solidsand-metals/.

10. Selvanayagam, C. S., J. H. Lau, et al., "Nonlinear thermal stress/strain analysis of copper filled TSV (through silicon via) and their flip-chip microbumps," Electron. Compon. Technol. Conf. (ECTC) 1073-1081, 2008.

11. R.E. Taylor, CINDAS Data Series on Materials Properties, Thermal Expansion of Solids, Vol 1-4, ASM International, 1998.

\section{Published By:}

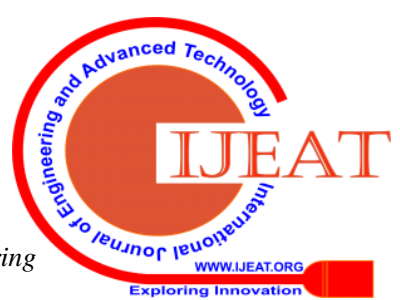


12. "Standard Test Method for Linear Thermal Expansion of Solid Materials with a Vitreous Silica Dilatometer," E 228-95, Annual Book of ASTM Standards, ASTM, 1995.

\section{AUTHORS PROFILE}

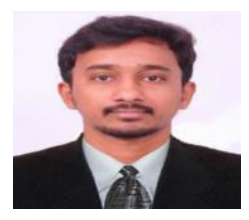

Nagarjuna Reddy Mudem is currently pursuing Master of Technology in the Department of CAD/CAM (Mechanical Engineering) in Marri Laxman Reddy Institute of Technology and Management (MLRITM). He received his B.Tech degree Mechanical Engineering in Sri Vasavi College of Engineering, JNTK University.

His current research interests include Automation, Computer Aided Engineering.

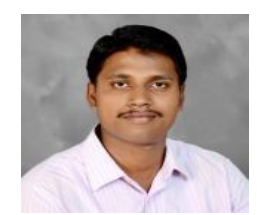

S. P. JANI, M.E., Ph.D. professor of mechanical engineering, has about 8 years of experience in teaching. A graduate and post graduate from Sethu Institute of Technology, Tamilnadu and did his Ph.D from Anna University. He was published more than 20 research articles in various national and international journals as well as conference. He has a research interest in PMCs and machining performance study. 